Article

\title{
Hop Extract Acts as an Antioxidant with Antimicrobial Effects against Propionibacterium Acnes and Staphylococcus Aureus
}

\author{
Natalja Weber ${ }^{1,+}$, Klaus Biehler ${ }^{2,+}$, Kay Schwabe ${ }^{3}$, Birgit Haarhaus ${ }^{1}$, Karl-W. Quirin ${ }^{4}$, \\ Uwe Frank $^{2}$, Christoph M. Schempp ${ }^{1}$ and Ute Wölfle ${ }^{1, *}$ (D) \\ 1 Research Centre skinitial, Department of Dermatology, University Medical Center, 79104 Freiburg, Germany; \\ natalja_weber@gmx.de (N.W.); birgit.haarhaus@uniklinik-freiburg.de (B.H.); \\ christoph.schempp@uniklinik-freiburg.de (C.M.S.) \\ 2 Institute for Infection Prevention and Hospital Epidemiology, Medical Center, University of Freiburg, 79106 \\ Freiburg, Germany; klaus.biehler@uniklinik-freiburg.de (K.B.); uwe.frank@uniklinik-freiburg.de (U.F.) \\ 3 BSI-Beauty Science Intelligence GmbH, 30855 Langenhagen, Germany; K.Schwabe@bsi-cosmetics.de \\ 4 Flavex Naturextrakte GmbH, 66780 Rehlingen, Germany; wq@flavex.com \\ * Correspondence: ute.woelfle@uniklinik-freiburg.de; Tel.: +49-761-270-68250 \\ + Both authors contributed equally to the paper.
}

Academic Editors: Maria Daglia, Simone Carradori and Annabella Vitalone

Received: 11 December 2018; Accepted: 3 January 2019; Published: 9 January 2019

\begin{abstract}
Acne is associated with hyperkeratosis, elevated levels of skin sebum and growth of Propionibacterium acnes (P. acnes) and Staphylococcus aureus (S. aureus). Furthermore, P. acnes promotes inflammation by inducing IL-6 production and oxidative stress. The aim of this study was to assess the antioxidant, anti-inflammatory and antibacterial potential of a hop- $\mathrm{CO}_{2}$-extract with $50 \%$ humulone and lupulone. The susceptibility of $P$. acnes and $S$. aureus to the hop extract was tested by using the broth microdilution technique. The minimal inhibitory concentrations (MIC) for P. acnes and S. aureus were 3.1 and $9.4 \mu \mathrm{g} / \mathrm{mL}$, respectively. In addition, the hop extract showed an antioxidative effect with a half maximal inhibitory concentration $\left(\mathrm{IC}_{50}\right)$ of $29.43 \mu \mathrm{g} / \mathrm{mL}$ as well as additional anti-inflammatory effects by reducing the IL- 6 expression ( $\mathrm{IC}_{50}: 0.8 \mu \mathrm{g} / \mathrm{mL}$ ). In addition, a gel formulation with $0.3 \%$ hop extract $(w / w)$ had antibacterial activity against $P$. acnes and $S$. aureus (inhibition zone value: $5.5 \mathrm{~mm}$ and $3 \mathrm{~mm}$, respectively) which was significantly superior to the placebo gel. The positive control (a gel with the antibiotic clindamycin) showed an inhibition zone of $9 \mathrm{~mm}$. Due to its antioxidant, anti-inflammatory and antibacterial effects hop extract might be a treatment option for acne-prone skin.
\end{abstract}

Keywords: acne; P. acnes; S. aureus; hop extract; antimicrobial activity; antioxidant activity

\section{Introduction}

Acne is the most common inflammatory skin disease from which $70-95 \%$ of all teenagers temporarily suffer. In about $19 \%$ acne continues also to adulthood [1]. Acne is characterized by hyperactivity of sebaceous glands. Increased sebum production (seborrhea) is triggered by a transient hormonal imbalance in favour of testosterone. Principally, acne shows an epidermal hyperproliferation that causes follicular hyperkeratosis (comedones) and perifollicular inflammation (papules and pustules). The most important pathogen linked to acne-prone skin is Propionibacterium acnes (P. acnes) [2]. P. acnes is a Gram-positive, anaerobic, immobile bacterium that populates skin pores and hair follicles. It grows on sebaceous, greasy skin and uses sebum as nutrient source [3]. Sebum plays a role in the pathogenesis of acne [4], because P. acnes releases lipases, proteases and hydrolases into the sebum which promotes oxidative stress, inflammation and tissue destruction [5]. Degraded 
hyaluronic acid can activate the Toll Like Receptor-2 (TLR-2) on follicular keratinocytes eventually leading to the production of pro-inflammatory cytokines (e.g., IL-6, IL-1, TNF- $\alpha$, or IL-8) $[6,7]$. On macrophages TLR-2 activation promotes the expression of IL- 8 and IL-12 which stimulate hyperkeratinisation, inflammation and oxidative stress $[3,8]$.

Previous studies have shown that $P$. acnes stimulates keratinocyte proliferation by activating the insulin-like growth factor 1 (IGF-1) receptor system [5]. Therefore, degreasing the skin is one treatment option for acne. Recently we were able to demonstrate that a face cleanser with hop extract has a mild and constant degreasing effect with excellent skin tolerability [9]. Xanthohumol and bitter acids ( $\alpha$-bitter acids like humulone and $\beta$-bitter acids like lupulone) from hop (Humulus lupulus L.) show antibacterial effects against $P$. acnes $[10,11]$.

Besides P. acnes also aerobic bacteria such as the skin commensal Staphylococcus aureus (S. aureus) are increased in their number in acne lesions [3,12]. S. aureus is a harmless Gram-positive coccus that populates skin and mucosa [13]. However, it can also cause inflammatory skin diseases with pustules (e.g., furuncles, abscesses and folliculitis) by the release of extracellular toxins and enzymes.

This is why antibiotics are widely used to treat acne. The use of antibiotics, however, may promote the emergence and spread of bacterial resistance. Resistant $P$. acnes strains have been described more than forty years ago [14]. Resistance of P. acnes to clindamycin, tetracycline and other antibiotics is increasing worldwide [8]. On average, about $50 \%$ of P. acnes strains have been reported as resistant against several antibiotics [14,15].

Methicillin resistant strains of $S$. aureus (MRSA) pose a challenge in the treatment of infections. Resistance arises usually by the acquisition of a gene encoding a penicillin-binding protein (PBP2a) with significantly lower affinity for $\beta$-lactams [16].

Therefore, new antiseptic and antimicrobial agents for the topical treatment of skin infections are needed. Plant extracts might serve as alternative treatment options for acne [3].

In this study, we tested a hop extract rich in humulones and lupulones for its antioxidant and anti-inflammatory effects in human primary keratinocytes (HPKs) and, in addition, we analysed its antibacterial properties. In this process we found antimicrobial activities against both P. acnes and S. aureus (including MRSA) and were also able to demonstrate that the gel formulation containing hop extract unfolds antibacterial activity superior to that of the placebo gel.

\section{Results}

\subsection{Antioxidant and Anti-Inflammatory Effect of Hop Extract}

Acne lesions contain a high Reactive Oxygen Species (ROS) and high pro-cytokine level. To test the antioxidant effect of hop extract we used as test system irradiated HPKs, because ultraviolet (UV) radiation induces extensive generation of ROS in the skin. The ROS scavenging activity of hop extract was determined by using the free radical sensitive fluorescent dye $\mathrm{CM}-\mathrm{H}_{2} \mathrm{DCFDA}$ in solar simulator-irradiated HPKs. We chose an irradiation dose of $8 \mathrm{~J} / \mathrm{cm}^{2}$ in all experiments because this dose induced pronounced ROS production without cytotoxic effects. We could demonstrate that hop extract reduced the formation of ROS-induced dichlorofluorescein (DCF) in a concentration-dependent manner, starting at a concentration of $2 \mu \mathrm{g} / \mathrm{mL}$. At a concentration of $32 \mu \mathrm{g} / \mathrm{mL}$ the effect was comparable to the potent antioxidant flavonoid luteolin (Figure 1A). The half maximal inhibitory concentration $\left(\mathrm{IC}_{50}\right)$ of hop extract was $29.43 \mu \mathrm{g} / \mathrm{mL}$. The reduced metabolic activity of HPKs caused by irradiation was rescued with $0.5 \mu \mathrm{g} / \mathrm{mL}$ hop extract. Furthermore, the hop extract was not toxic or phototoxic within the tested concentration range. Only at the highest tested concentration $(32 \mu \mathrm{g} / \mathrm{mL})$ a slight inhibition of the metabolic activity could be detected (Figure 1B). Hop extract also reduced IL-6 production after solar simulator-irradiation of HPKs ( $\mathrm{IC}_{50}: 0.8 \mu \mathrm{g} / \mathrm{mL}$ ) (Figure 1C). The effect was even stronger compared to the positive control luteolin. 

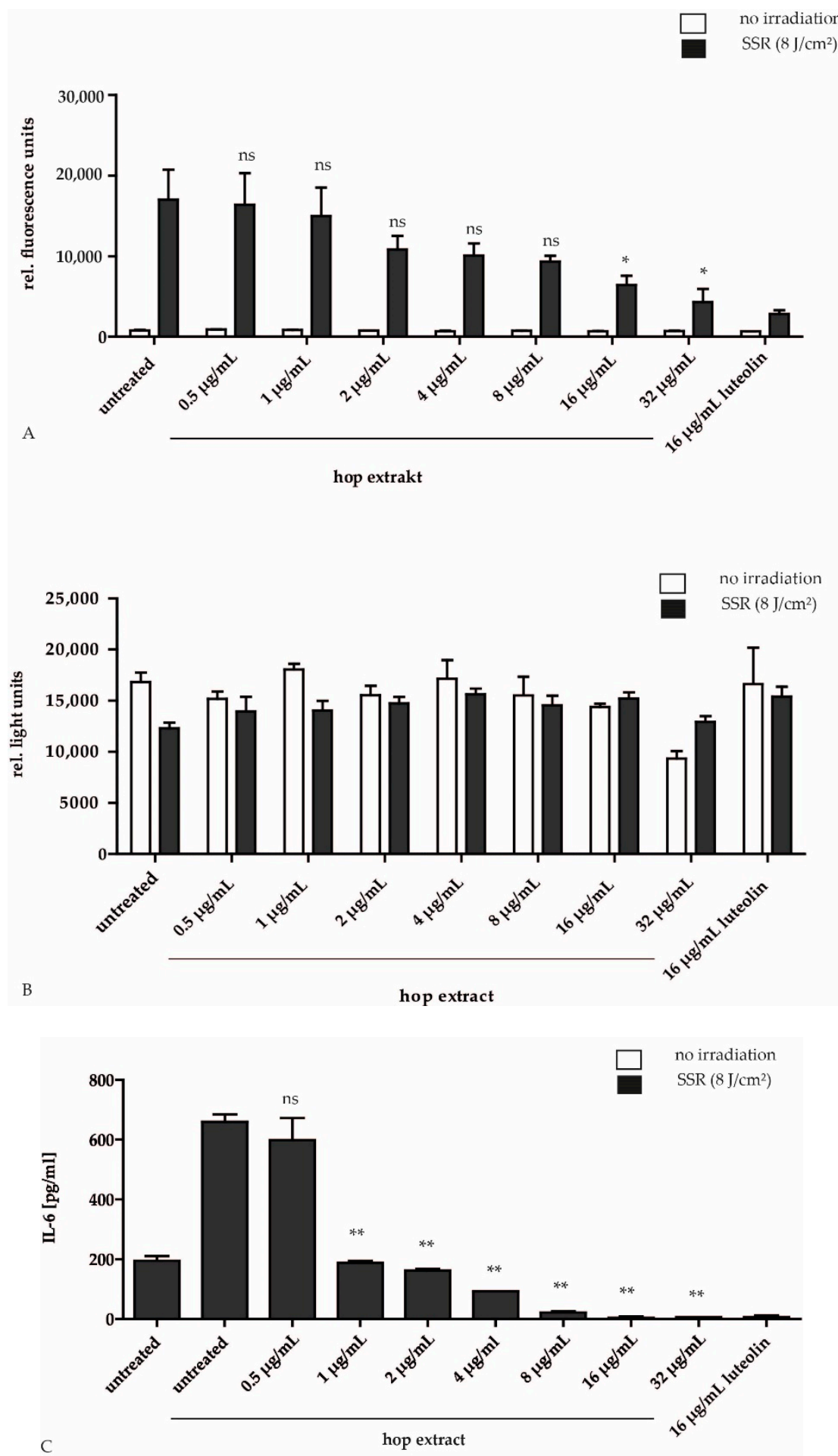

Figure 1. Effect of hop extract on irradiation-induced ROS level and cell viability in HPKs. HPKs were incubated for $30 \mathrm{~min}$ with different concentrations of hop extract as indicated or $16 \mu \mathrm{g} / \mathrm{mL}$ luteolin as positive control before $\mathrm{CM}-\mathrm{H}_{2}$ DCFDA was added. (A). A test of the cell viability showed that the hop extract was not toxic or phototoxic to the cells (B). HPKs were irradiated using a solar simulator and incubated for $24 \mathrm{~h}$ with hop extract at various concentrations as indicated. Then the IL- 6 concentration of the supernatant was measured with an ELISA. Hop extract reduced irradiation-induced IL-6 production (C). Data are expressed as means \pm SD of three independent experiments (ns, not significant, $p \leq 0.05$ $(*)$ and $p \leq 0.01(* *)$. 


\subsection{Antibacterial Effect of Hop Extract}

P. acnes colonization is a relevant factor causing hyperkeratosis and inflammation in acne pathogenesis. The antibacterial effect of hop extract was analysed in a microdilution test with different bacterial strains of the human skin microbiome. Four different strains of P. acnes (human skin commensals that prefer anaerobic growth conditions) and four different strains of $S$. aureus (human skin commensals that grow under aerobic growth conditions) were tested. Clindamycin was used as positive control. Clindamycin belongs to the lincosamide class of antibiotics that block the protein synthesis of anaerobic and aerobic bacteria including P. acnes and S. aureus. Hop extract inhibited the growth of $P$. acnes with a minimal inhibitory concentration (MIC) of $3.1 \mu \mathrm{g} / \mathrm{mL}$ in all $P$. acnes strains tested, including the standard strain P. acnes ATCC 6919. Only P. acnes 201 showed a MIC between 3.1 and $6.2 \mu \mathrm{g} / \mathrm{mL}$. The MIC of clindamycin was less than $0.2 \mu \mathrm{g} / \mathrm{mL}$ except for the strain P. acnes 1990 with an MIH of $0.8 \mu \mathrm{g} / \mathrm{mL}$ (Table 1). The MIC of hop extract in S. aureus strains was on average $9.4 \mu \mathrm{g} / \mathrm{mL}$ (range $6.25 \mu \mathrm{g} / \mathrm{mL}$ to $12.5 \mu \mathrm{g} / \mathrm{mL}$ ) including MRSA and non MRSA strains. For clindamycin, the MIC was for all non-MRSA strains on average $0.126 \mu \mathrm{g} / \mathrm{mL}$ (range $0.003 \mu \mathrm{g} / \mathrm{mL}$ to $0.25 \mu \mathrm{g} / \mathrm{mL}$ ). Although clindamycin very effectively inhibited the growth of non-MRSA strains it could only inhibit the growth of the MRSA strain 4810 at a concentration of $>50 \mu \mathrm{g} / \mathrm{mL}$. In contrast, hop extract inhibited MRSA already at a concentration of $12.5 \mu \mathrm{g} / \mathrm{mL}$ (Table 2).

Table 1. Antibacterial activity (Minimal inhibitory concentration, MIC) of hop extract against P. acnes strains determined in the microdilution test. P. acnes strains were isolated from acne lesions or ordered by ATCC.

\begin{tabular}{ccc}
\hline P. acnes Strains & Hop Extract $\mu \mathrm{g} / \mathrm{mL}$ & Clindamycin $\mu \mathrm{g} / \mathrm{mL}$ \\
\hline P. acnes 199 & 3.1 & 0.8 \\
P. acnes 201 & $3.1-6.2$ & $<0.2$ \\
P. acnes 209 & 3.1 & $<0.2$ \\
P. acnes ATCC 6919 & 3.1 & $<0.2$ \\
\hline
\end{tabular}

Table 2. Antibacterial activity (Minimal inhibitory concentration, MIC) of hop extract against S. aureus strains determined in the microdilution test. S. aureus were isolated from pyrogenic skin disorders or ordered by ATCC.

\begin{tabular}{ccc}
\hline S. aureus Strains & Hop Extract $\mu \mathrm{g} / \mathrm{mL}$ & Clindamycin $\mu \mathrm{g} / \mathrm{mL}$ \\
\hline S. aureus ATCC 29213 & $6.25-12.5$ & 0.25 \\
S. aureus ATCC 25923 & $6.25-12.5$ & $<0.125$ \\
S. aureus 2407 & 6.25 & 0.003 \\
S. aureus MRSA 4810 & 12.5 & $>50$ \\
\hline
\end{tabular}

\subsection{Antibacterial Effect of a Botanical gel with Hop Extract}

In order to test if the hop extract is also effective in a topical gel preparation, an agar diffusion test was performed. $0.3 \%$ hop extract was used in the botanical gel, together with other botanical actives, that is, salicylic acid, Salix daphnoides bark extract, Gentiana lutea root extract, Leptospermum scoparium branch/leaf oil (Manuka oil), Mentha arvensis herb oil and the preservatives sodium levulinate and sodium anisate. The placebo gel contained none of these active ingredients. The botanical gel significantly inhibited the growth of P. acnes compared to the placebo gel ( $4.9 \mathrm{vs}$. $2.0 \mathrm{~mm}$ inhibition zone). The placebo showed also a slight inhibition, possibly due to ingredients such as jojoba oil that also displays moderate antibacterial effects. The positive control was a commercially available gel containing not only clindamycin but also benzoyl peroxide. It inhibited the bacterial growth strongly with an inhibition zone of $9.0 \mathrm{~mm}$. We also tested another commercially available acne gel with retinol and Boswellia serrata extract, which showed no antibacterial effect (Figure 2A).

When tested on S. aureus the botanical gel also showed a trend to an increased inhibition zone compared to placebo but this effect was not statistically significant. The positive control clindamycin 
showed an inhibition zone of $2 \mathrm{~mm}$ in MRSA while the botanical gel had no effect (Figure 2B). The effect of the positive control was possibly mediated by benzoyl peroxide, because clindamycin alone showed only moderate activity against MRSA in the microdilution test.
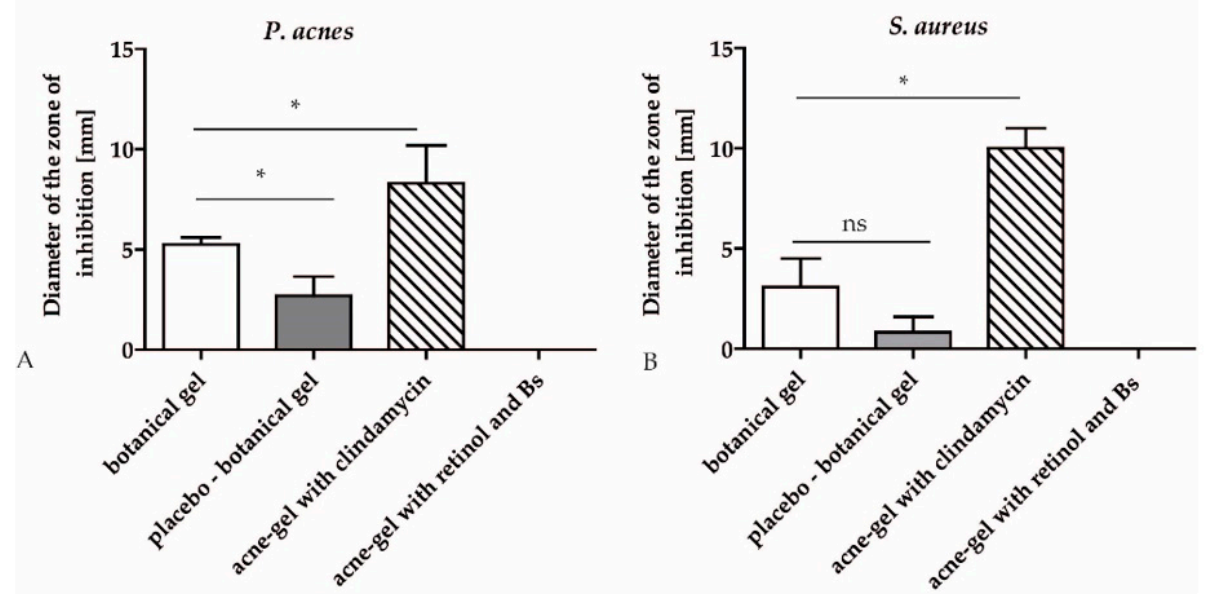

Figure 2. Antibacterial activity of hop extract against $P$. acnes strains determined in the agar diffusion test. Diameter of the zone of inhibition $[\mathrm{mm}]$ is indicated. A commercially available acne-gel with clindamycin served as positive control. Another commercial acne-gel with retinol and a Boswellia serrata extract (Bs) was additionally tested (A). The antibacterial activity of hop extract against S. aureus strains was determined in the agar diffusion test. The diameter of the inhibition zone [mm] is indicated. The acne-gel with clindamycin served as positive control. The acne-gel with retinol and a Boswellia serrata extract (Bs) was a comparative product (B). Data are expressed as means \pm SD of two independent experiments (ns, not significant, $p \leq 0.05\left(^{*}\right)$ ).

\section{Discussion}

The topical standard treatment of acne includes benzoyl peroxide and retinoids as well as topical antibiotics such as clindamycin. Retinol as vitamin A derivative reacts comedolytic and is known for its reduction of keratinocyte mitosis, hyperkeratinisation and inflammation [3]. However, these treatment options have also some disadvantages, because benzoyl peroxide and retinoids on the one hand can irritate the skin and frequently applied topical antibiotics on the other hand may lead to bacterial resistance, so that these antibiotics become useless in severe infections [17]. Therefore, plant extracts are interesting new sources of antibacterial agents. The hop extract used in this study was effective against $P$. acnes and $S$. aureus including MRSA, so that a botanical gel with hop extract might be a useful alternative in the treatment of acne. In a patch test on the back of 30 healthy volunteers the botanical gel did not cause any skin irritation (data not shown).

Good antibacterial activity of isolated compounds and plant extracts are $10 \mu \mathrm{g} / \mathrm{mL}$ and $100 \mu \mathrm{g} / \mathrm{mL}$, respectively [2,18]. The hop extract has a high antimicrobial activity against P. acnes (MIC of $3.1 \mu \mathrm{g} / \mathrm{mL}$ ) with additional antioxidant and anti-inflammatory activities as demonstrated in hop-treated irradiated HPKs.

Antibacterial activities of a hop- $\mathrm{CO}_{2}$ extract could also be demonstrated against Corynebacterium xerosis and Staphylococcus epidermidis [19]. Furthermore the growth of other gram-positive bacteria (Bacillus anthracis, Bacillus subtilis, Corynebacterium diphteriae, Sarcinia lutea, Sarcinia Faecalis, Lactobacillus brevis including species of Micrococcus, Mycobacterium, Streptomycetes, Listeria and Costridium) [19-24] as well as some gram-negative bacteria (Helicobacter pylori and Brucella species) could be inhibited by humulone and lupulone [24-26]. The isoprenyl side chains of the hop acids interfere with the bacterial cell plasma membrane and cause a leakage of this membrane which inhibits the transport of sugar and amino acids $[19,27]$. The antibacterial action of hop compounds has also proton ionophore activity and a pronounced redox reactivity, causing cellular oxidative damage. This interference with redox-sensitive pathways is also responsible for antiviral effects of the hop extract. [28]. 
In addition, especially lupulone and xanthohumulone can penetrate biofilms of Staphylococcus species including methicillin resistant strains and reduce the number of bacteria in it. Furthermore lupulone and xanthohumol could also eliminate the bacteria at higher concentrations $(\sim 60 \mu \mathrm{g} / \mathrm{mL}$ for xanthohumol and $\sim 125 \mu \mathrm{g} / \mathrm{mL}$ for lupulone) [29].

Many medical plants with anti-inflammatory or antibacterial effects are interesting sources for the treatment of acne $[3,30]$. When the hop extract is compared to other plant extracts it appears to be very active. Other extracts for example, herbal ball extract (a combination of Centella asiatica extract with Kalmegh (Andrographis paniculata)), rosmarinic acid, a phenolic compound from Rosmarinus officinalis, Centella asiatica extract alone, or Rosa damascena methanolic extract had a MIC of $31.2 \mu \mathrm{g} / \mathrm{mL}$, $62.5 \mu \mathrm{g} / \mathrm{mL}, 5 \mathrm{mg} / \mathrm{mL}$ or $2 \mathrm{mg} / \mathrm{mL}$ respectively [2,3,31,32]. Other plant extracts with antibacterial activities at lower concentrations include Punica granatum bark extract containing $13 \%$ ellagic acid with a MIC of 15.6 against $P$. acnes and $7.8 \mu \mathrm{g} / \mathrm{mL}$ against $S$. aureus [33]. Angelica anomala was also very effective against P. acnes with a MIC of $15.6 \mu \mathrm{g} / \mathrm{mL}$ [34]. In accordance to our results Yamaguchi and colleagues [11] demonstrated that xanthohumol and lupulones from Humulus lupulus possess strong inhibitory activity against $P$. acnes (MIC $0.1-3 \mu \mathrm{g} / \mathrm{mL}$ ) [11]. The here tested hop extract possesses also lupulones and humulones but no xanthohumol. In a recent paper by Bartmańska and colleagues it was shown that various polar extracts and isolated flavonoids obtained from spent hop cones also display pronounced antimicrobial effects against a wide range of bacteria including methicillin resistant S. aureus [24]. Other polar constituents that occur in hop extracts such as catechin and kaempferol also show antibacterial activities, for example by inhibiting the lipase of P. acnes [35] Furthermore Di Sotto and colleagues have shown that hydroalcoholic extracts of hop with phenolic compounds display antiviral and antioxidative effects. [28]

The contribution of P. acnes to the pathogenesis of acne also involves the induction of ROS production and release of pro-inflammatory cytokines Sharma et al. described that Echinacea extract normalizes elevated cytokine IL-6 levels comparable to hop extract [36].

Although hop extract is the most important component of the botanical gel tested here, the gel also contains willow bark extract, Mentha arvensis oil and Leptospermum scoparium oil which display additional useful effects in the topical treatment of acne. Willow balk extract has keratolytic activity and removes cells that plug the secretory duct of sebaceous glands. Mentha arvensis oil (field mint oil) with $90 \%$ menthol activates the cold-sensing $\mathrm{Ca}^{2+}$ permeable non-selective cation channel TRPM8 (Transient Receptor Potential Melastatin 8) [37] and causes a cold sensation and itch relief. Leptospermum scoparium oil (Manuka oil) displays additional anti-bacterial activity. Manuka oil inhibited in 40 consecutive aromatogramms the growth of $S$. aureus isolated from patient samples (unpublished data of biovis Diagnostik, MVZ GmbH, Limburg, Germany). The antimicrobial effect of the botanical gel cannot be attributed to a certain substance or extract contained in the gel. Several of the botanical ingredients, that is, hop extract (= humulus lupulus extract), salicylic acid, willow birch extract and leptospermium extract certainly may display antimicrobial effects. Therefore, in the agar test the effect of the whole composition was compared to the placebo gel without the botanical ingredients and to other commercially available topical products. This allows the conclusion that all the botanical ingredients together display antimicrobial effects that are superior to the placebo gel.

The acne-gel with retinol and Boswellia serata extract had no effect in our agar dilution test. However, it has been shown that Boswellia serrata extract is highly effective at low concentrations against aerobic and anaerobic bacteria including P. acnes (MIC: $1 \mu \mathrm{g} / \mathrm{mL}$; [38]) while 11-keto- $\beta$-boswellic acid was not active against these bacteria. Therefore, it was speculated that the effective components of Boswellia might rather be essential oils than boswellic acids. The Boswellia serrata extract in the tested acne-gel possibly did not contain enough antibacterial substances, or these substances were not released from the acne-gel. One possibility to make substances bioavailable is the preparation of a substance-loaded myristic acid microemulsion. Liu and Huang described such a preparation for curcumin. As curcumin acts as an anti-inflammatory and anti-microbial agent against P. acnes and Staphylococcus epidermidis, a bacterium that is also involved in acne, the curcumin microemulsion might 
also be suitable for the treatment of acne [39-41]. In the study presented here hop extract obviously could be released from the botanical gel without microemulsions, because in the agar diffusion test the growth of $P$. acnes and $S$. aureus was inhibited effectively.

A review on dermatologically relevant plants to treat acne with focus on controlled clinical studies revealed tea tree oil (Melaleuca alternifolia) as one of the most active plant extracts. In a single-blind, randomized study $5 \%$ tea tree oil was compared with the gold standard $5 \%$ benzoyl peroxide. Both preparations showed after 3 months of treatment comparable improvement of the symptoms [42]. This result was confirmed in a vehicle-controlled randomized double-blind study over 45 days in 60 acne-prone patients [43,44]. Interestingly, tea tree oil is related to manuka oil that is present in our botanical gel with hop extract. In addition, a $2 \%$ lotion with green tea (Camellia sinensis) extract improved acne symptoms within 6 weeks (application twice daily) in a prospective, non-randomized study with 20 acne patients [44-46]. Tannins and flavonoids contained in the green tea extract might be responsible for this anti-acne effect. Flavonoids display antibacterial activity and tannins have anti-inflammatory effects. Epigallocatechin gallate (EGCG) as main active compound in green tea is sebosuppressive and displays antibacterial effects against $P$. acnes. [47]. The phloroglucinol derivatives humulone and lupulone from hop extract might have similar effects.

\section{Materials and Methods}

\subsection{Chemicals}

Clindamycin hydrochlorid (European Pharmacopeia Reference Standard) was purchased by Council of Europe EDQM (Strasbourg, France), the brain heart infusion (BHI) medium by Oxoid (München, Germany), Mueller Hinton (MH) broth, cation adjusted by Becton, Dickinson (Heidelberg, Germany) and Muller Hinton-agar by Roth GmbH (Karlsruhe, Germany).

\subsection{Hop Extract}

The supercritical hop $\mathrm{CO}_{2}$-extract was produced by Flavex (Rehlingen, Germany) and dissolved in DMSO. In brief, hop flowers (Humulus lupulus flos) were dried, powdered and extracted with high pressure supercritical $\mathrm{CO}_{2}$. The genuine $\mathrm{CO}_{2}$ extract is further processed by $\mathrm{CO}_{2}$ counter current column extraction in order to remove the essential oil to a large extend. The flavour reduced supercritical extract which does not contain xanthohumol, was standardized to $49-51 \%$ humulones ( $\alpha$-acids consisting of humulone, adhumulone and cohumulone) and lupulones ( $\beta$-acids consisting of n-lupulone, adlupulone and colupulone) by sunflower oil addition [19]. The $\mathrm{CO}_{2}$ extract selectively yields lipophilic compounds, therefore no polar compounds such as tannins, flavonoids or other polyphenols are present in the extract. The primary extract is a thick material difficult to handle, thus, sunflower oil is added to obtain a more viscous extract and to standardize the extract to a defined range of active compounds. The ratio of humulones and lupulones may show some seasonal fluctuations. The concentration of humulones varies between 31 und 35\% and the concentration of lupulones varies between 15 and 19\%. The ratio of humulones to lupulones lies between 1.6 and 2.3 to 1 . This indicates that the variations are not very pronounced. This is important as the antibacterial activity of hop acids increases with decreasing polarity. In lupulones compared to humulones a hydroxyl-group is replaced by an isoprenyl side chain. Therefore lupulones are a bit more lipophilic and therefore a bit more active than humulones (Figure 3A).

The final product represents a drug/extract ratio of about $4-5.3 / 1$ and contains less than $2 \%$ volatile constituents.

\subsection{HPLC Analysis of Hop $\mathrm{CO}_{2}$-Extract}

All solvents were of HPLC grade and supplied by VWR International GmbH (Darmstadt, Germany). International Calibration Extract (ICE) is used as standard and dissolved in methanol with $0.6-1.0 \mathrm{mg} / \mathrm{mL}$ concentration. The hop $\mathrm{CO}_{2}$-extract was dissolved under sonication in methanol 
with $0.5-1.5 \mathrm{mg} / \mathrm{mL}$ concentration and filtered through a PTFE filter with $0.45 \mu \mathrm{m}$ pore diameter before injection.

A Merck Hitachi LaChrom Elite HPLC system was used, consisting of auto sampler L-2200, pump L-2130, DAD detector L-2420, column oven L-2350, operated with software EZ Chrom Elite Version 3.3.2 Build 1037 (SP2) from Agilent Technologies, Inc., Santa Clara, CA, USA; column Lichrospher $100 \mathrm{RP}-18 \mathrm{e}(5 \mu \mathrm{m}), 250 \times 4$ (mm length $\times$ internal diameter), Merck KGaA (Darmstadt, Germany). Eluent A was water acidified with o-phosphoric acid 85\% to pH 2.3-2.6, eluent B methanol; eluent composition: $14 \% \mathrm{~A}, 86 \% \mathrm{~B}$, isocratic for $20 \mathrm{~min}$. Eluent flow was $1 \mathrm{~mL} / \mathrm{min}$, oven temperature $35^{\circ} \mathrm{C}$, detector $314 \mathrm{~nm}$, injection volume $10 \mu \mathrm{L}$. Humulones and lupulones were identified and quantified using the Calibration Extract as external standard. A HPLC fingerprint of hop- $\mathrm{CO}_{2}$ extract is shown in Figure 3B.

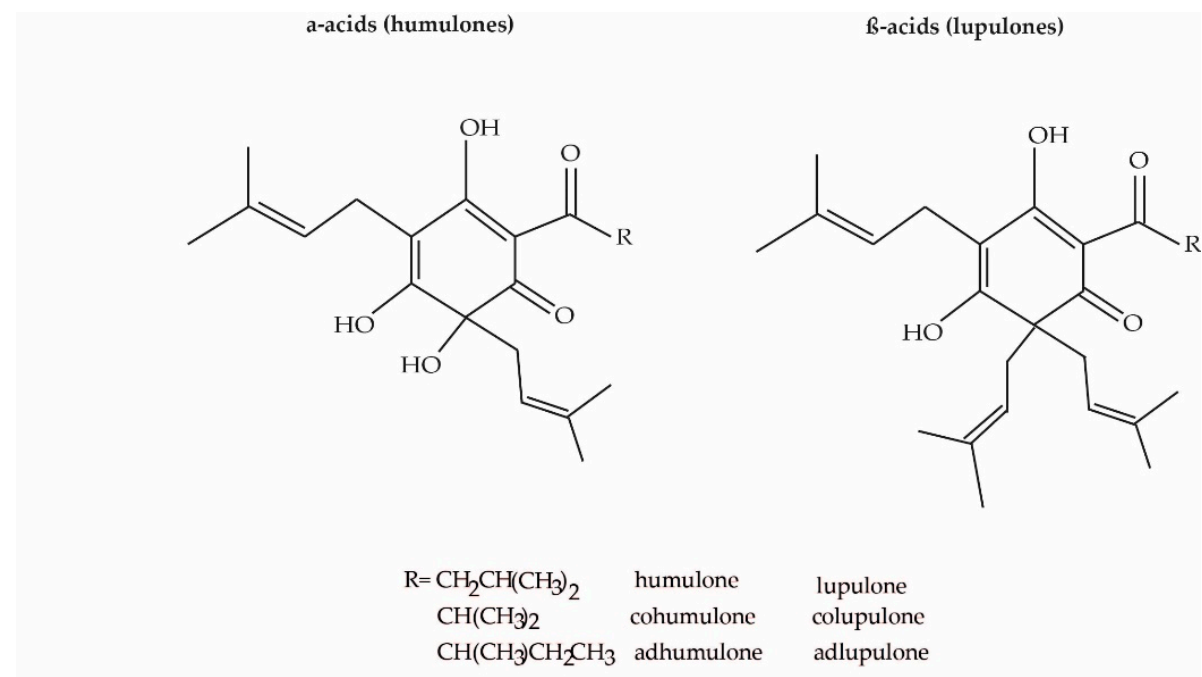

A

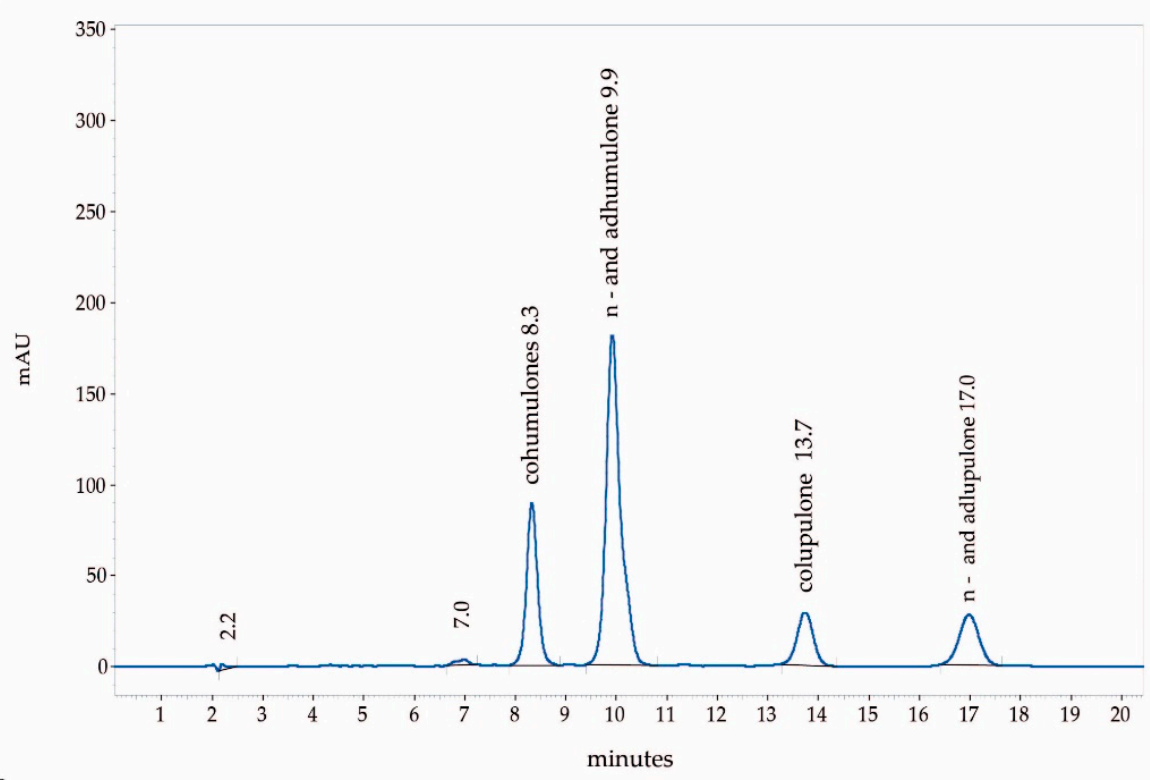

B

Figure 3. Structural formula of humulones and lupulones (A). HPLC fingerprint of hop- $\mathrm{CO}_{2}$ extract, flavour reduced and standardised to 50\% humulones and lupulones (B).

\subsection{INCI of the Tested Gels}

Botanical gel with hop extract (Velan Clear Skin, VELAN skincare, Freiburg, Germany) INCI: Aqua, Alcohol, Dicaprylyl Ether, Simmondsia Chinensis Seed Oil, Bambusa Arundinacea 
Stem Powder, Glycerin, Sodium Stearoyl Glutamate, Hydrogenated Vegetable Glycerides, Salicylic Acid, Salix Daphnoides Bark Extract, Humulus Lupulus Extract, Gentiana Lutea Root Extract, Leptospermum Scoparium Branch/Leaf Oil, Mentha Arvensis Herb Oil, Helianthus Annuus Seed Oil Unsaponifiables, Xanthan Gum, Glyceryl Caprylate, Tocopherol, Cetearyl Alcohol, Sodium Levulinate, Sodium Anisate, Lysolecithin, Sclerotium Gum, Pullulan, Silica, Limonene.

Placebo of the botanical gel (Beauty Science Intelligence $\mathrm{GmbH}$, Langenhagen, Germany)

INCI: Aqua, Alcohol, Dicaprylyl Ether, Simmondsia Chinensis Seed Oil, Bambusa Arundinacea Stem Powder, Sodium Stearoyl Glutamate, Hydrogenated Vegetable Glycerides, Xanthan Gum, Cetearyl Alcohol, Tocopherol, Lysolecithin, Sclerotium Gum, Pullulan, Silica.

Acne-gel with clindamycin (Duac Acne Gel, GlaxoSmithKline GmbH \& Co. KG, München, Germany)

INCI: carbomer, dimeticone, disodium lauryl sulfosuccinate, disodium edetate, glycerol, silica (dental type), poloxamer 182, purified water, sodium hydroxide, clindamycin phosphate and benzoyl peroxide.

Acne-gel with Retinol and Boswellia serrata (Bs) extract (BiRetix Duo, IFC Dermatologie Deutschland GmbH, Ainring, Germany)

INCI: Aqua, Glycerin, Butylene Glycol, Sodium Acrylate/Sodium Acryloyldimethyl Taurate Copolymer, Polysorbate 80, Dimethyl Isosorbide, Benzyl Alcohol Isohexadecane, Hydrogenated Lecithin, Trehalose, Salicylic Acid, Tocopherol, Hydroxypinacolone retinoate, Phenoxyethanol, Lecithin, Dehydroacetic Acid, Palmitoyl Hydroxypropyltrimonium Amylopectin/Glycerin Crosspolymer, Oryza Sativa Bran Extract, Polysorbate 20, Boswellia Serrata Extract, Honey Extract, Retinol, Ascorbyl PalmitateBeta-sitosterol, Squalane, Glycine Soja Oil, Sodium Hydroxide, Oligopeptide-10, Citric Acid.

\subsection{Cultivation of Bacteria}

In the present study bacteria strains of P. acnes and S. aureus were analysed. All isolates came from patient isolates of the Institute for Infection Prevention and Hospital Epidemiology, Medical Centre-University of Freiburg (P. acnes 199, P. acnes 201, P. acnes 209) or were purchased by American Type Culture Collections (ATCC; P. acnes ATCC 6919 was used as reference strain). Furthermore S. aureus ATCC 29213, S. aureus ATCC 25923, S. aureus 2407 and S aureus 4810 (MRSA) were analysed. The test strains were pre-cultivated on appropriate agar plates ( $\mathrm{MH}$ for S. aureus, BHI for P. acnes). Fresh colonies were suspended in PBS. The final turbidity was assessed according to that of a 0.5 McFarland Standard.

\subsection{Microdilution Test}

The minimal inhibitory concentration (MIC) of bacterial growth was determined by mixing the bacterial culture with the broth $\mathrm{BHI}$ or $\mathrm{MH}$. P. acnes were grown in $\mathrm{BHI}$ medium under anaerobic conditions using an Anaerobe Container System (GasPak EZ) at $37^{\circ} \mathrm{C}$ for 3 days and the turbidity of the bacterial suspension was adjusted to an optical density of 0.14 with PBS to obtain about $1 \times 10^{8}$ colony-forming units (CFU)/mL. S. aureus was grown in $\mathrm{MH}$ medium under aerobic conditions at $37^{\circ} \mathrm{C}$ overnight and the bacteria were adjusted photometrical to $0.08\left(10^{8} \mathrm{CFU} / \mathrm{mL}\right)$ in PBS. $50 \mu \mathrm{L}$ $P$. acnes suspension or $50 \mu \mathrm{L}$ S. aureus suspension were added to $5 \mathrm{~mL}$ 2-fold concentrated BHI or $\mathrm{MH}$ medium. $100 \mu \mathrm{L}$ of this suspension (corresponding to 50,000 bacteria) was used per well in a 96 round bottom well plate. $100 \mu \mathrm{L}$ sterile water with hop extract was added to each well. The hop extract was dissolved in DMSO and serial diluted in a 2-fold dilution series to achieve 9 concentrations from $0.19 \mu \mathrm{g} / \mathrm{mL}$ to $50 \mu \mathrm{g} / \mathrm{mL}$. Clindamycin served as positive control. DMSO (solvent of the hop extract) and water (solvent of clindamycin) served as negative controls. It was dissolved in distilled water and was used in 2-fold dilution series to achieve 9 concentrations from $32 \mu \mathrm{g} / \mathrm{mL}$ to $0.125 \mu \mathrm{g} / \mathrm{mL}$. The $P$. acnes samples were then incubated in an anaerobic environment at $37^{\circ} \mathrm{C}$ for $24 \mathrm{~h}$. $S$ aureus samples were incubated for $16 \mathrm{~h}$ in an aerobic environment. The lowest hop concentration required to inhibit bacterial growth was defined as MIC. Each sample dilution was tested in a duplicate manner 
with biological replicates. The assay was performed according the guidelines of Clinical and Laboratory Standards Institute (CLSI).

\subsection{Agar Diffusion Test}

The antibacterial activity of several gel preparations was evaluated by the agar diffusion test. P. acnes was incubated in $\mathrm{BHI}$ for 3 days at $37^{\circ} \mathrm{C}$ under anaerobic conditions and adjusted to yield approximately $10^{4} \mathrm{CFU} / \mathrm{mL}$ PBS. Agar plates were filled with $12 \mathrm{~mL}$ of BHI-Agar or MH agar. The agar was inoculated by spreading P. acnes or S. aureus over the entire agar surface and allowed to dry. Then 4 holes with a diameter of $3 \mathrm{~mm}$ were punched aseptically with a cork drill. The gel formulations were placed in the holes respectively. Afterwards the agar plates with $P$ acnes were incubated at $37^{\circ} \mathrm{C}$ under anaerobic condition for 3-4 days. The agar plates with $S$. aureus were incubated at $37^{\circ} \mathrm{C}$ under aerobic condition for 1 day. The gel base (placebo), the botanical gel (containing hop extract) and an acne-gel (containing retinol and Boswellia serata extract) were used. A gel with $1 \%(w / w)$ clindamycin and $5 \%(w / w)$ benzoyl peroxide served as positive control. The antibacterial activity was estimated by measuring the diameter of the zone of inhibition that appeared as clear zone. All diffusion tests were performed in two independent experiments and antibacterial activity was expressed as mean \pm standard deviation.

\subsection{Cultivation of Human Primary Keratinocytes (HPKs)}

HPKs were prepared from juvenile foreskin or adult skin obtained from dermatological surgeries and cultured according to the method of Rheinwald and Green [48] in DermaLife medium (Cell System, Goisdorf, Germany). All cells were cultured at $37{ }^{\circ} \mathrm{C}$ in a humidified atmosphere with $5 \% \mathrm{CO}_{2}$. The study for the in vitro research with primary keratinocytes was approved by the ethics committee of the University of Freiburg (no.432/18).

\subsection{Intracellular ROS Measurement}

Intracellular reactive oxygen species (ROS) formation was quantified using $5 \mu \mathrm{MCM}-\mathrm{H}_{2} \mathrm{DCFDA}$ reagent (5-(and-6)-chloromethyl-2', $7^{\prime}$-dichlorodihydrofluorescein diacetate) as described [49]. In brief, after incubation with different substance concentrations from $0.5-32 \mu \mathrm{g} / \mathrm{mL}$ for $30 \mathrm{~min}$, the cells were incubated with a $5 \mu \mathrm{M} \mathrm{CM}-\mathrm{H}_{2}$ DCFDA solution at $37^{\circ} \mathrm{C}$ in the dark and then irradiated with $8 \mathrm{~J} / \mathrm{cm}^{2}$ using a solar simulator (Model 81192, Oriel, Stratford, CT [50] equipped with a $1000 \mathrm{~W}$ Xenon arc lamp, Model 81192, Oriel, Stratford, CT, USA). The generation of ROS was measured by the change in fluorescence due to the intracellular production of $2^{\prime}, 7^{\prime}$-dichlorofluorescein (DCF) using excitation and emission wavelengths of $428 \mathrm{~nm}$ and $516 \mathrm{~nm}$, respectively, with a spectrophotometer (Sirius HT-TRF microplate reader, BioTek, Bad Friedrichshall, Germany). After ROS measurement the cells were incubated for a further $4 \mathrm{~h}$ at $37^{\circ} \mathrm{C}$ and the cytotoxicity assay ViaLight Plus ATP assay (Cambrex, Verviers, Belgium) was performed according to the manufacturer's instructions [51]. The method is based on the bioluminescent measurement of ATP that is present in metabolically active cells. Luciferase catalyses the formation of light from ATP and luciferin. The emitted light intensity is directly proportional to the ATP concentration and is measured with a luminometer (Sirius HT, BioTek, Bad Friedrichshall, Germany).

\subsection{IL-6 ELISA}

HPKs were treated for 30 min with hop extract in the indicated concentrations of $16 \mu \mathrm{g} / \mathrm{mL}$ luteolin as positive control. Subsequently, the cells were irradiated with $8 \mathrm{~J} / \mathrm{cm}^{2}$ using a solar simulator, washed once with PBS and supplemented with new medium. $24 \mathrm{~h}$ post irradiation IL-6 concentrations were analysed in the supernatants by an ELISA (R\&D systems, Wiesbaden, Germany) according to the manufacturer's protocol. Data were expressed as mean \pm SD of two experiments. 


\subsection{Statistical Analysis}

The data were analysed using the unpaired Student $t$-test (two-tailed) and statistical significance was established at $p \leq 0.05\left(^{*}\right)$ and $p \leq 0.01\left(^{* *}\right)$.

\section{Conclusions}

Taken together, hop extract shows not only antibacterial activity against $P$. acnes and $S$. aureus but also has antioxidant and anti-inflammatory effects. This makes it a promising topical ingredient to treat acne-prone skin and to reduce the application of antibiotics in mild forms of acne.

Author Contributions: N.W. and K.B. performed the microdilution and agar diffusions test. K.S. produced the tested botanical and placebo gel. B.H. performed all cell culture experiments (e.g., ROS assay and IL-6 ELISA). K.-W.Q. produced and analysed the hop extract. U.F. co-wrote the paper. C.M.S. coordinated the project and co-wrote the paper. U.W. supervised the laboratory experiments and wrote the paper.

Funding: The research centre receives funding from the Software AG Stiftung and DAMUS DONATA e.V. The founding sponsors had no role in the design of the study; in the collection, analyses, or interpretation of data; in the writing of the manuscript and in the decision to publish the results.

Conflicts of Interest: U. Wölfle and C.M. Schempp hold a patent on the topical application of bitter taste receptor agonists and receive royalties from Velan Skincare. The study was performed without industrial funding.

\section{References}

1. Svensson, A.; Ofenloch, R.F.; Bruze, M.; Naldi, L.; Cazzaniga, S.; Elsner, P.; Goncalo, M.; Schuttelaar, M.-L.A.; Diepgen, T.L. Prevalence of skin disease in a population-based sample of adults from five European countries. Br. J. Dermatol. 2018, 178, 1111-1118. [CrossRef] [PubMed]

2. Jantarat, C.; Sirathanarun, P.; Chuchue, T.; Konpian, A.; Sukkua, G.; Wongprasert, P.; Jantarat, C.; Sirathanarun, P.; Chuchue, T.; Konpian, A.; et al. In Vitro Antimicrobial Activity of Gel Containing the Herbal Ball Extract against Propionibacterium acnes. Sci. Pharm. 2018, 86, 8. [CrossRef] [PubMed]

3. Sinha, P.; Srivastava, S.; Mishra, N.; Yadav, N.P. New Perspectives on Antiacne Plant Drugs: Contribution to Modern Therapeutics. Available online: https:/ /www.hindawi.com/journals/bmri/2014/301304/abs / (accessed on 17 October 2018).

4. Dessinioti, C. Acne Pathogenesis: What We Have Learned Over the Years. In Pathogenesis and Treatment of Acne and Rosacea; Zouboulis, C.C., Katsambas, A.D., Kligman, A.M., Eds.; Springer: Berlin/Heidelberg, Germany, 2014; pp. 61-70. ISBN 978-3-540-69375-8.

5. Isard, O.; Knol, A.C.; Ariès, M.F.; Nguyen, J.M.; Khammari, A.; Castex-Rizzi, N.; Dréno, B. Propionibacterium acnes activates the IGF-1/IGF-1R system in the epidermis and induces keratinocyte proliferation. J. Investig. Dermatol. 2011, 131, 59-66. [CrossRef] [PubMed]

6. Omer, H.; McDowell, A.; Alexeyev, O.A. Understanding the role of Propionibacterium acnes in acne vulgaris: The critical importance of skin sampling methodologies. Clin. Dermatol. 2017, 35, 118-129. [CrossRef] [PubMed]

7. Esser, P.R.; Wölfle, U.; Dürr, C.; von Loewenich, F.D.; Schempp, C.M.; Freudenberg, M.A.; Jakob, T.; Martin, S.F. Contact sensitizers induce skin inflammation via ROS production and hyaluronic acid degradation. PLoS ONE 2012, 7, e41340. [CrossRef] [PubMed]

8. Dessinioti, C.; Katsambas, A. Propionibacterium acnes and antimicrobial resistance in acne. Clin. Dermatol. 2017, 35, 163-167. [CrossRef] [PubMed]

9. Weber, N.; Schwabe, K.; Schempp, C.M.; Wölfle, U. Effect of a botanical cleansing lotion on skin sebum and erythema of the face: A randomized controlled blinded half-side comparison. J. Cosmet. Dermatol. 2018. [CrossRef] [PubMed]

10. Chen, W.; Becker, T.; Qian, F.; Ring, J. Beer and beer compounds: Physiological effects on skin health. J. Eur. Acad. Dermatol. Venereol. 2014, 28, 142-150. [CrossRef]

11. Yamaguchi, N.; Satoh-Yamaguchi, K.; Ono, M. In vitro evaluation of antibacterial, anticollagenase and antioxidant activities of hop components (Humulus lupulus) addressing acne vulgaris. Phytomedicine Int. J. Phytother. Phytopharm. 2009, 16, 369-376. [CrossRef]

12. Degitz, K.; Ochsendorf, F. Akne. J. Dtsch. Dermatol. Ges. 2017, 15, 709-722. [CrossRef] 
13. Larkin, E.A.; Carman, R.J.; Krakauer, T.; Stiles, B.G. Staphylococcus aureus: The toxic presence of a pathogen extraordinaire. Curr. Med. Chem. 2009, 16, 4003-4019. [CrossRef] [PubMed]

14. Walsh, T.R.; Efthimiou, J.; Dréno, B. Systematic review of antibiotic resistance in acne: An increasing topical and oral threat. Lancet Infect. Dis. 2016, 16, 23-33. [CrossRef]

15. Kosmadaki, M.; Katsambas, A. Topical treatments for acne. Clin. Dermatol. 2017, 35, 173-178. [CrossRef] [PubMed]

16. Lindsay, J.A. Hospital-associated MRSA and antibiotic resistance-what have we learned from genomics? Int. J. Med. Microbiol. 2013, 303, 318-323. [CrossRef]

17. Leyden, J.J. Antibiotic resistance in the topical treatment of acne vulgaris. Cutis 2004, 73, 6-10.

18. Kuete, V. Potential of Cameroonian plants and derived products against microbial infections: A review. Planta Med. 2010, 76, 1479-1491. [CrossRef] [PubMed]

19. Dumas, E.R.; Michaud, A.E.; Bergeron, C.; Lafrance, J.L.; Mortillo, S.; Gafner, S. Deodorant effects of a supercritical hops extract: Antibacterial activity against Corynebacterium xerosis and Staphylococcus epidermidis and efficacy testing of a hops/zinc ricinoleate stick in humans through the sensory evaluation of axillary deodorancy. J. Cosmet. Dermatol. 2009, 8, 197-204. [CrossRef] [PubMed]

20. Lewis, J.C.; Alderton, G.; Carson, J.F.; Reynolds, D.M.; Maclay, W.D. Lupulon and humulon-antibiotic constituents of hops. J. Clin. Investig. 1949, 28, 916-919. [CrossRef]

21. Simpson, W.J. Cambridge Prize Lecture. Studies on the Sensitivity of Lactic Acid Bacteria to Hop Bitter Acids. J. Inst. Brew. 1993, 99, 405-411. [CrossRef]

22. Behr, J.; Vogel, R.F. Mechanisms of Hop Inhibition Include the Transmembrane Redox Reaction. Appl. Environ. Microbiol. 2010, 76, 142-149. [CrossRef]

23. Zanoli, P.; Zavatti, M. Pharmacognostic and pharmacological profile of Humulus lupulus L. J. Ethnopharmacol. 2008, 116, 383-396. [CrossRef] [PubMed]

24. Bartmańska, A.; Wałecka-Zacharska, E.; Tronina, T.; Popłoński, J.; Sordon, S.; Brzezowska, E.; Bania, J.; Huszcza, E. Antimicrobial Properties of Spent Hops Extracts, Flavonoids Isolated Therefrom and Their Derivatives. Molecules 2018, 23, 2059. [CrossRef]

25. Shapouri, R.; Mehdi, R. Evaluation of antimicrobial effect of hops extracts on intramacrophages Brucella abortus and B. melitensis. Jundishapur J. Microbiol. 2011, 4, 51-58.

26. Ohsugi, M.; Basnet, P.; Kadota, S.; Ishii, E.; Tamura, T.; Okamura, Y.; Namba, T. Antibacterial activity of traditional medicines and an active constituent lupulone from Humulus lupulus against Helicobacter pylori. J. Tradit. Med. 1997, 14, 186-191.

27. Schmalreck, A.F.; Teuber, M. Structural features determining the antibiotic potencies of natural and synthetic hop bitter resins, their precursors and derivatives. Can. J. Microbiol. 1975, 21, 205-212. [CrossRef]

28. Di Sotto, A.; Checconi, P.; Celestino, I.; Locatelli, M.; Carissimi, S.; De Angelis, M.; Rossi, V.; Limongi, D.; Toniolo, C.; Martinoli, L.; et al. Antiviral and Antioxidant Activity of a Hydroalcoholic Extract from Humulus lupulus L. Available online: https:/ / www.hindawi.com/journals/omcl/2018/5919237/ (accessed on 28 December 2018).

29. Bogdanova, K.; Röderova, M.; Kolar, M.; Langova, K.; Dusek, M.; Jost, P.; Kubelkova, K.; Bostik, P.; Olsovska, J. Antibiofilm activity of bioactive hop compounds humulone, lupulone and xanthohumol toward susceptible and resistant staphylococci. Res. Microbiol. 2018, 169, 127-134. [CrossRef] [PubMed]

30. Nasri, H.; Bahmani, M.; Shahinfard, N.; Moradi Nafchi, A.; Saberianpour, S.; Rafieian Kopaei, M. Medicinal Plants for the Treatment of Acne Vulgaris: A Review of Recent Evidences. Jundishapur J. Microbiol. 2015, 8 , e25580. [CrossRef] [PubMed]

31. Budhiraja, A.; Dhingra, G. Development and characterization of a novel antiacne niosomal gel of rosmarinic acid. Drug Deliv. 2015, 22, 723-730. [CrossRef]

32. Tsai, T.-H.; Tsai, T.-H.; Wu, W.; Te-Peng Tseng, J.; Tsai, P.-J. In vitro antimicrobial and anti-inflammatory effects of herbs against Propionibacterium acnes. Food Chem. 2010, 119, 964-968. [CrossRef]

33. Panichayupakaranant, P.; Tewtrakul, S.; Yuenyongsawad, S. Antibacterial, anti-inflammatory and anti-allergic activities of standardised pomegranate rind extract. Food Chem. 2010, 123, 400-403. [CrossRef]

34. Kim, S.-S.; Kim, J.-Y.; Lee, N.H.; Hyun, C.-G. Antibacterial and anti-inflammatory effects of Jeju medicinal plants against acne-inducing bacteria. J. Gen. Appl. Microbiol. 2008, 54, 101-106. [CrossRef] [PubMed] 
35. Falcocchio, S.; Ruiz, C.; Pastor, F.; Saso, L.; Diaz, P. Propionibacterium acnes GehA lipase, an enzyme involved in acne development, can be successfully inhibited by defined natural substances. J. Mol. Catal. B-Enzym. 2006, 40, 132-137. [CrossRef]

36. Sharma, M.; Schoop, R.; Suter, A.; Hudson, J.B. The potential use of Echinacea in acne: Control of Propionibacterium acnes growth and inflammation. Phytother. Res. PTR 2011, 25, 517-521. [CrossRef]

37. Peier, A.M.; Moqrich, A.; Hergarden, A.C.; Reeve, A.J.; Andersson, D.A.; Story, G.M.; Earley, T.J.; Dragoni, I.; McIntyre, P.; Bevan, S.; et al. A TRP channel that senses cold stimuli and menthol. Cell 2002, 108, 705-715. [CrossRef]

38. Weckesser, S.; Engel, K.; Simon-Haarhaus, B.; Wittmer, A.; Pelz, K.; Schempp, C.M. Screening of plant extracts for antimicrobial activity against bacteria and yeasts with dermatological relevance. Phytomedicine Int. J. Phytother. Phytopharm. 2007, 14, 508-516. [CrossRef] [PubMed]

39. Panahi, Y.; Fazlolahzadeh, O.; Atkin, S.L.; Majeed, M.; Butler, A.E.; Johnston, T.P.; Sahebkar, A. Evidence of curcumin and curcumin analogue effects in skin diseases: A narrative review. J. Cell. Physiol. 2019, 2, 1165-1178. [CrossRef] [PubMed]

40. Liu, C.-H.; Huang, H.-Y. In Vitro Anti-Propionibacterium Activity by Curcumin Containing Vesicle System. Chem. Pharm. Bull. 2013, 61, 419-425. [CrossRef]

41. Liu, C.-H.; Huang, H.-Y. Antimicrobial Activity of Curcumin-Loaded Myristic Acid Microemulsions against Staphylococcus epidermidis. Chem. Pharm. Bull. 2012, 60, 1118-1124. [CrossRef]

42. Bassett, I.B.; Pannowitz, D.L.; Barnetson, R.S. A comparative study of tea-tree oil versus benzoylperoxide in the treatment of acne. Med. J. Aust. 1990, 153, 455-458.

43. Enshaieh, S.; Jooya, A.; Siadat, A.H.; Iraji, F. The efficacy of 5\% topical tea tree oil gel in mild to moderate acne vulgaris: A randomized, double-blind placebo-controlled study. Indian J. Dermatol. Venereol. Leprol. 2007, 73, 22-25.

44. Reuter, J.; Wölfle, U.; Weckesser, S.; Schempp, C. Which plant for which skin disease? Part 1: Atopic dermatitis, psoriasis, acne, condyloma and herpes simplex. J. Dtsch. Dermatol. Ges. J. Ger. Soc. Dermatol. JDDG 2010, 8, 788-796. [CrossRef] [PubMed]

45. Elsaie, M.L.; Abdelhamid, M.F.; Elsaaiee, L.T.; Emam, H.M. The efficacy of topical $2 \%$ green tea lotion in mild-to-moderate acne vulgaris. J. Drugs Dermatol. JDD 2009, 8, 358-364. [PubMed]

46. The complete German Commission E monographs. Therapeutic guide to herbal medicines. Available online: https:/ / www.amazon.com/Complete-German-Commission-Monographs-Therapeutic/ dp/096555550X (accessed on 1 September 1998).

47. Yoon, J.Y.; Kwon, H.H.; Min, S.U.; Thiboutot, D.M.; Suh, D.H. Epigallocatechin-3-gallate improves acne in humans by modulating intracellular molecular targets and inhibiting P. acnes. J. Investig. Dermatol. 2013, 133, 429-440. [CrossRef] [PubMed]

48. Rheinwald, J.G.; Green, H. Formation of a keratinizing epithelium in culture by a cloned cell line derived from a teratoma. Cell 1975, 6, 317-330. [CrossRef]

49. Wölfle, U.; Esser, P.R.; Simon-Haarhaus, B.; Martin, S.F.; Lademann, J.; Schempp, C.M. UVB-induced DNA damage, generation of reactive oxygen species and inflammation are effectively attenuated by the flavonoid luteolin in vitro and in vivo. Free Radic. Biol. Med. 2011, 50, 1081-1093. [CrossRef] [PubMed]

50. Wölfle, U.; Heinemann, A.; Esser, P.R.; Haarhaus, B.; Martin, S.F.; Schempp, C.M. Luteolin prevents solar radiation-induced matrix metalloproteinase-1 activation in human fibroblasts: A role for p38 mitogen-activated protein kinase and interleukin-20 released from keratinocytes. Rejuv. Res. 2012, 15, 466-475. [CrossRef]

51. Woelfle, U.; Laszczyk, M.N.; Kraus, M.; Leuner, K.; Kersten, A.; Simon-Haarhaus, B.; Scheffler, A.; Martin, S.F.; Müller, W.E.; Nashan, D.; et al. Triterpenes promote keratinocyte differentiation in vitro, ex vivo and in vivo: A role for the transient receptor potential canonical (subtype) 6. J. Investig. Dermatol. 2010, 130, 113-123. [CrossRef]

Sample Availability: Samples of the compounds are available from the authors.

(c) 2019 by the authors. Licensee MDPI, Basel, Switzerland. This article is an open access article distributed under the terms and conditions of the Creative Commons Attribution (CC BY) license (http:/ / creativecommons.org/licenses/by/4.0/). 